\title{
Bioelectrical impedance phase angle in sport: a systematic review
}

\author{
Olivia Di Vincenzo ${ }^{1}$, Maurizio Marra ${ }^{1 *}$ (D) and Luca Scalfi ${ }^{2}$
}

\begin{abstract}
Background: Phase angle (PhA) is a raw BIA variable that has been gaining attention in recent years because it is supposed to be an index of the ratio between extracellular and intracellular water, body cell mass, and cellular integrity.

The aim of this systematic review was to evaluate the variability of PhA between different sports and its relationships with sport performance. Additionally, we investigated whether PhA depends on gender or age, and analyzed the differences between athletes and controls.

Methods: A systematic research using PubMed, Scopus and Web of Science up to June 2019 was performed. Selection criteria included studies on subjects who practice sports in planned and continuous modality at competitive or elite level.

Results: Thirty-five papers met the inclusion criteria (twenty-one cross-sectional data, fourteen longitudinal data). A few but convincing studies have shown that mean PhA is higher in athletes vs. controls. PhA increases with age and is likely to be higher in male than female athletes. A large variability in PhA is observed for the same sport, while it is still uncertain to what extent PhA differs between various sports. There are no clear relationships of PhA with sport performance or training/untraining.

Conclusion: It is still to be defined to what extent PhA varies between different sports and changes with training/ untraining. It can be argued that for a given sport much more data should be collected in a systematic way and for a period of time appropriate in order to determine changes and trends. This is even more crucial in the case of intervention studies.
\end{abstract}

Keywords: Phase angle, Bioimpedance analysis, Athletes, Sport, Physical activity

\section{Background}

Bioelectrical impedance analysis (BIA) is a widely used, non-invasive field method for assessing body composition, which measures the electrical characteristics of human body either at $50 \mathrm{kHz}$ (single-frequency BIA) or at several frequencies in the range $1-1000 \mathrm{kHz}$ (multifrequency BIA and $\mathrm{BIS}=$ bioimpedance spectroscopy). Impedance $(\mathrm{Z})$ is the opposition of the body to an alternating current, resulting from resistance $(R)$ to the current that flows through tissue containing water plus electrolytes, and reactance $(\mathrm{Xc})$, which is associated with the capacitive component of tissues (e.g. cell membranes and tissue interfaces) [1]. In addition, phase angle (PhA),

\footnotetext{
*Correspondence: maurizio.marra@unina.it

'Department of Clinical Medicine and Surgery, Federico II University Hospital, Via S. Pansini 5, 80138 Naples, Italy

Full list of author information is available at the end of the article
}

which is also stated as the arctangent of the Xc to $R$ ratio, describes the angular shift (phase difference) between voltage and current sinusoidal waveforms; in humans the current reaches at regular intervals its maximum/minimum peaks after the voltage (positive PhA values) and this lag is most likely due to cell membranes and tissue interfaces $[1,2]$.

Using BIA, total body water (TBW) and fat-free mass (FFM) can be estimated by means of predictive equations, which include BIA variables and almost always variables such as age, stature and weight. Alternatively, directlymeasured raw BIA variables, such as $\mathrm{PhA}$ at $50 \mathrm{kHz}$ or impedance ratio $(I R=$ the ratio between $Z$ at higher frequencies and $\mathrm{Z}$ al lower frequencies), have been gaining attention because they are considered indexes of water distribution (ratio between extracellular water-ECW and

(C) The Author(s). 2019 Open Access This article is distributed under the terms of the Creative Commons Attribution 4.0 International License (http://creativecommons.org/licenses/by/4.0/), which permits unrestricted use, distribution, and 
intracellular water-ICW), body cell mass (BCM), and cellular integrity [2]. PhA and IR have been shown to be significantly associated with muscle strength and physical activity $[3,4]$ and to vary between gender and with aging $[5,6]$ in line with that is known about physiological changes in $\mathrm{BCM}$ and $\mathrm{ECW} / \mathrm{ICW}$.

In sport science the assessment of body composition has different applications such as identifying individual's characteristics critical to performance, evaluating the effects of training programs, managing weight strategies in weight-category sports, etc. In this regard, BIA has been used in athletes as a field technique for estimating TBW and FFM. Indeed, there is still limited research and it is uncertain to what accuracy BIA may be used in athletes for single measurements or for tracking body composition changes [7]. Even less attention has been paid to raw BIA data. A recent review has shown that Bioelectrical Impedance Vector Analysis (BIVA) of both R and $\mathrm{Xc}$ has yielded some conflicting results on the use if BIA for identifying dehydration $[8,9]$. On the other hand, at least in theory, the use of PhA or IR may be crucial in evaluating athletes' body composition because it can provide useful data on the percentage of BCM in FFM (structural muscle quality) in both cross-sectional and longitudinal studies. A recent paper [10] supported this view showing in 202 athletes that PhA significantly correlated with ICW and the ICW/ECW ratio. In this context, the purpose of this systematic review was to evaluate the variability of PhA among athletes and its relationship with sports performance. Additionally, we wanted to investigate whether PhA differs between athletes and controls or between different sports.

\section{Methods}

\section{Search strategy}

Two authors (ODV and MM) independently performed a literature search up to June 2019 of the electronic databases PubMed, Scopus, and Web of Science.

The following terms were used as search strategy string: ("bioelectrical impedance" OR "bioimpedance" OR BIA) AND "phase angle" AND (spor* OR athlet* OR "physical activity" OR fitness OR train*).

The Preferred Reporting Items for Systematic Reviews and Meta-Analyses (PRISMA) [11] were followed for performing the present review. Due to the study type (systematic review), ethical approval was not necessary according to local registration.

\section{Eligibility criteria}

The PICOS strategy was defined as follows: "P" (patients) corresponded to participants of any age, sex or ethnicity, "I" (intervention) designated regular physical exercise at amateur, elite and professional level, "C" (comparison) indicated no physical exercise or low physical activity, "O" (outcome) corresponded to PhA, and " $\mathrm{S}$ " (study design) indicated cross-sectional or longitudinal studies.

The following eligibility criteria were applied: a) studies on athletes following exercise programmes with or without a control group; b) papers published from inception to June 2019; c) full papers published in peerreviewed journals or in relevant congress proceedings; d) studies evaluating body composition using BIA phasesensitive devices and yielding overt data on $\mathrm{PhA}$; e) studies written in English. No restriction was applied to age of participants and sample size.

Studies with the following criteria were excluded: a) non-healthy athletes; b) articles without full-text availability, opinion pieces, review articles and editorials.

\section{Study selection and data extraction}

Titles and abstracts from the electronic searches were screened independently by two authors (ODV and MM). The full texts of selected articles were checked by the same two authors to consider the fit with eligibility criteria. A third reviewer (LS) revised any differences in opinion to make a final decision.

An electronic database was designed to store all relevant data. Data were extracted separately by two investigators (ODV and MM), and in the event of disagreement LS cross-examined doubtful data. The following data were extracted: first author, year of publication, country of origin, study type (cross-sectional or longitudinal), study population (sample size, age, gender, period of data collection, and country of residence), type of sport/exercise, presence of a control groups, assessment method and when they were studied.

\section{Risk of bias}

Methodological quality was assessed using [1] the Quality Assessment Tool for Observational Cohort and CrossSectional Studies in observational studies [2]; the Quality Assessment Tool for Before-After (Pre-Post) Studies With No Control Group in before-after (pre-post) studies. Both tools are recommended by the National Institute of Health, U.S. Department of Health and Human Services [12], which were based on Evidence-based Practice Centers (AHRQ) criteria (Additional file 1: Table S1). The [1] tool consists of 14 criteria and the [2] tool of 12 criteria that are used to assess quality, including whether the population studied was clearly specified and defined, whether the outcome assessors were blinded, and an assessment of the participation rate. The criteria were classified as "yes", "cannot be determined", "not reported", or "not applicable".

Quality rates were good, fair, or poor as judged by two independent observers (ODV and MM) following the instructions given by the National Institute of Health and 
taking into consideration the number of positive responses. High risk of bias translates to a rating of poor quality. Low risk of bias translates to a rating of good quality.

\section{Results}

\section{Study selection}

The literature search revealed a total of 196 studies. After exclusion of duplicates $(n=99)$, by screening titles and abstracts 59/97 studies were excluded because included ill subjects or subjects not practicing a sport or because they were not otherwise appropriated. Five reviews were also excluded. The full text of 38 studies was independently examined by two reviewers. Thirty-five studies (21 cross-sectional and 14 longitudinal studies, of which 12 giving also crosssectional data) meeting the inclusion criteria and being suitable for the systematic review (Fig. 1).

\section{Study characteristics}

The main characteristics of the selected studies are summarized in Tables 1 and 2. The articles were published from 1992 to 2019 but most of them (85.7\%) appeared in the last 10 years. Overall, 3703 athletes (3172 in crosssectional and 531 in longitudinal studies) were taken into consideration in this systematic review, with more males ( $n=2699)$ than females $(n=1264)$, and including children, adolescents and adults. Most of the cross-sectional studies were carried out in Europe $(n=14)$, especially in Italy $(n=9)$, six in the United States, Central or South-America and only one in Asia. All the longitudinal studies were performed in Europe $(n=7$ in Italy, $n=2$ Spain and Portugal, and $\mathrm{n}=1$ in France, UK and Czech Republic). Eleven studies evaluated soccer players (34.4\%), eight cyclists (22.9\%), six judo players (17.1\%), six swimmers (17.1\%), six volleyball players (17.1\%), five triathlon athletes $(14.3 \%)$, four water polo athletes $(11.4 \%)$, four handball (11.4\%) and four basketball players (11.4\%). Other 31 sport specialties were considered in only one study.

Of the 35 papers analysed, 32 (91.3\%) used the classic BIA, one used Tanita (2.9\%), one used Inbody720 (2.9\%) and one used mBCA Seca (2.9\%). Piccoli et al. [13] and Matias et al. [14] measured PhA with bioelectrical impedance spectroscopy (BIS) analyser. In 29 studies phase

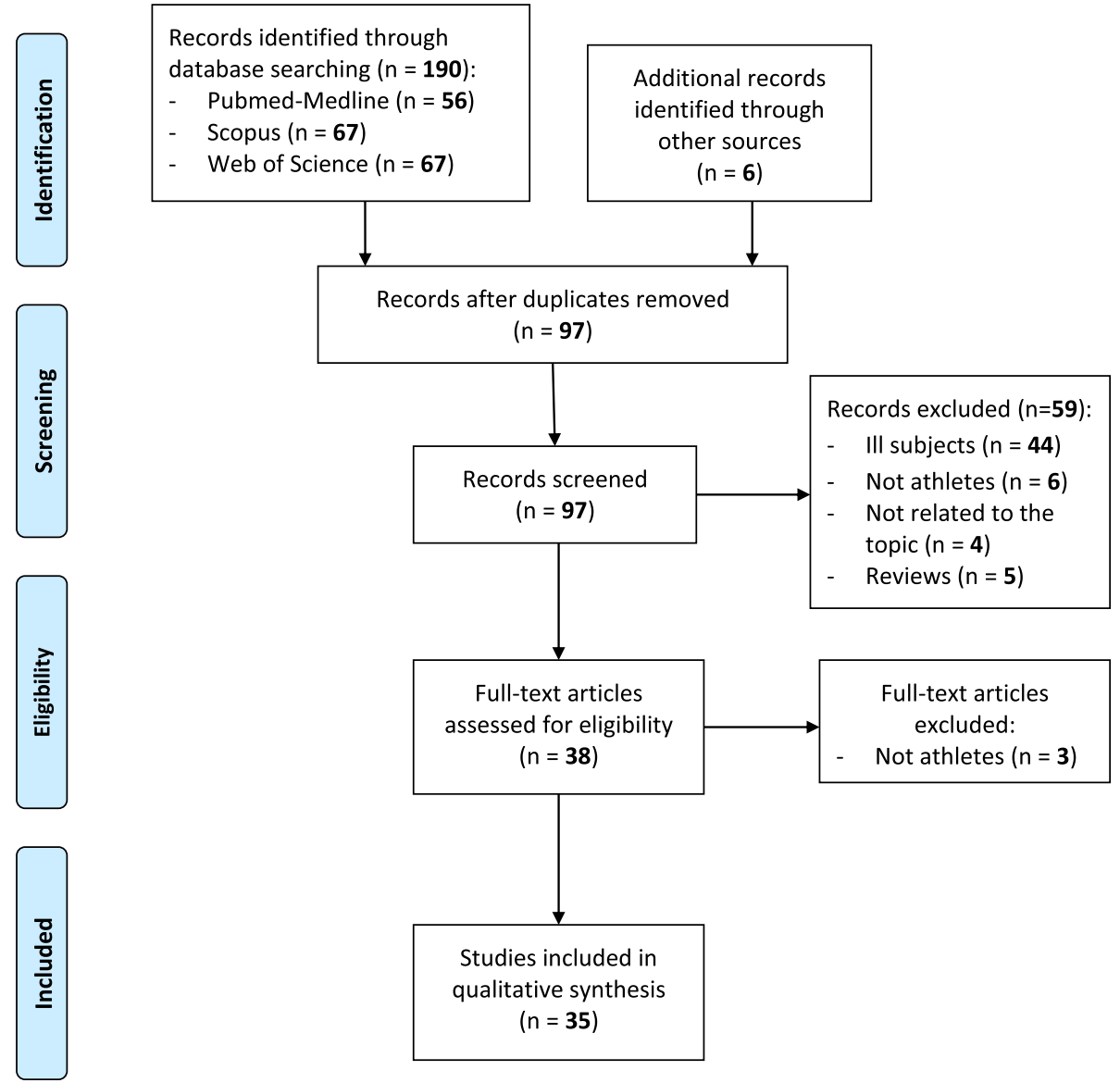

Fig. 1 Flowchart on the search and selection of articles included in the review 
Table 1 Descriptive characteristics of cross-sectional included studies $(n=21)$

\begin{tabular}{|c|c|c|c|c|c|}
\hline $\begin{array}{c}\text { Author } \\
\text { Year } \\
\text { Pubblication }\end{array}$ & 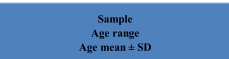 & $\begin{array}{l}\text { Sport } \\
\text { Level }\end{array}$ & Time period they were seen & $\begin{array}{l}\text { BIA Device } \\
\text { Electrode Distribution } \\
\text { Frede } \\
\text { Freugenes }\end{array}$ & Main results BLA PhA \\
\hline $\begin{array}{c}\text { Hotrobagyi } \\
1992 \\
\text { Orignal Article }\end{array}$ & 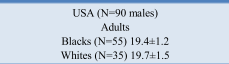 & $\begin{array}{c}\text { Football } \\
\text { Professional }\end{array}$ & $\begin{array}{l}\text { During one tessing gession, abstained from } \\
\text { exercise on the day of testing }\end{array}$ & $\begin{array}{l}\text { RLL Spectrimm II system } \\
\text { Whole body } \\
\text { NR } \\
50 \mathrm{kHIz}\end{array}$ & White football players had sigifificantly lower PhA values than blacks. \\
\hline $\begin{array}{c}\text { D'Alessando } \\
2007 \\
\text { Original Article }\end{array}$ & $\begin{array}{c}\text { Italy (N=110 females) } \\
\text { Adolescents } \\
\text { Rhyyhthric Gymrasts }(\mathrm{N}-55) \quad 15.2+2.2 \\
\text { COntrols }(\mathrm{N}=55) \\
15.0 \pm 2.0\end{array}$ & $\begin{array}{l}\text { Rhyhhmic Gymmastic } \\
\text { Subelite }\end{array}$ & $\begin{array}{l}\text { During regular training sessions, far from } \\
\text { important competitions }\end{array}$ & $\begin{array}{l}\text { BIASTAA, Akerm } \\
\text { Whole-body } \\
\text { NR } \\
50 \mathrm{kHz}\end{array}$ & PhA values were within the normal distribution for age and sex. \\
\hline $\begin{array}{c}\text { Piveoli } \\
2007 \\
\text { Orignal Article }\end{array}$ & 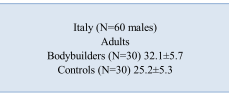 & $\begin{array}{l}\text { Bodybuilding } \\
\text { Professional }\end{array}$ & $\mathrm{NR}$ & 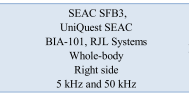 & Bodybuilders showedd a higher PhA than control subjects in agrecement with results obained by BIS. \\
\hline 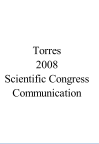 & $\begin{array}{l}\text { Brazil (N=158 males) } \\
\text { Adolescents, Adults } \\
13-48 \text { yrs }\end{array}$ & 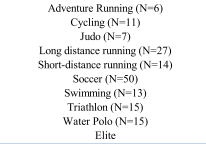 & $\mathrm{NR}$ & $\begin{array}{l}\text { BIA 101-Q, RJL Systems } \\
\text { Whole-body } \\
\text { NR } \\
50 \mathrm{kHz}\end{array}$ & $\begin{array}{l}\text { PhA was lower in adolescents (10-19 years) than in young adults } 20-29 \text { years) and increased steeply with age (30-39 years) within } \\
\text { the sane specialty (socer). PhA was positively correlated with BMI. }\end{array}$ \\
\hline $\begin{array}{c}\text { Ney } \\
2009 \\
\text { Orignal Article }\end{array}$ & $\begin{array}{l}\text { Brazil (N-20 males) } \\
\text { Adolecse-nts Adults } \\
18.114 .1\end{array}$ & $\begin{array}{c}\text { Swinming } \\
\text { Elite }\end{array}$ & During regular training sessions & $\begin{array}{c}\text { RLL Quntum system } \\
\text { Wholob-body } \\
\text { NR } \\
50 \mathrm{kHz}\end{array}$ & 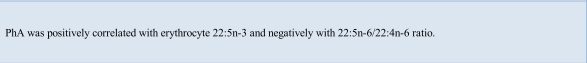 \\
\hline $\begin{array}{c}\text { Marra } \\
2009 \\
\text { Original Atricle }\end{array}$ & 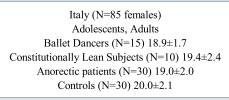 & $\begin{array}{c}\text { Ballet Dance } \\
\text { Elite }\end{array}$ & $\mathrm{NR}$ & $\begin{array}{l}\text { BIA } 101 \text { analyzer, Akern } \\
\text { Whole-body and Segmental (arms and } \\
\text { legs) } \\
\text { Mean of the left- and right- side } \\
50 \text { HHz }\end{array}$ & Female balle dancers had significantly higher PhA values, for both the whole body and limbs, compared with controls. \\
\hline $\begin{array}{c}\text { Mala } \\
2010 \\
\text { Original Article }\end{array}$ & 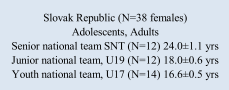 & $\begin{array}{c}\text { Volleyball } \\
\text { Professional }\end{array}$ & 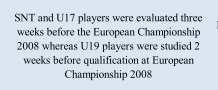 & $\begin{array}{l}\text { BIA 2000 M device, Datat Input GmbH } \\
\text { Whole-body } \\
\text { NR } \\
\text { NR }\end{array}$ & 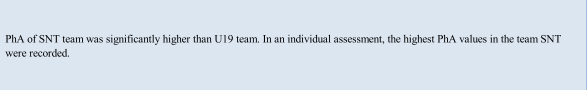 \\
\hline $\begin{array}{c}\text { Kim } \\
2010 \\
\text { Scientific Congress } \\
\text { Communication }\end{array}$ & 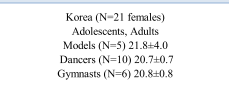 & 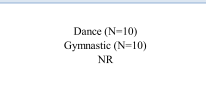 & NR & $\begin{array}{l}\text { InBody } 720, \text { Biospace Co. } \\
\text { Whole-body } \\
\text { NR } \\
50 \mathrm{kHz}\end{array}$ & PhA was higher in gymmasts han in dancers. \\
\hline$\underset{\substack{\text { Maly } \\
2011 \\
\text { Original Article }}}{n}$ & 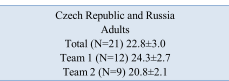 & $\begin{array}{c}\text { Volleyball } \\
\text { Elite }\end{array}$ & $\begin{array}{l}\text { In the morning hours before a mutual } \\
\text { preparation match }\end{array}$ & $\begin{array}{l}\text { BIA } 2000 \mathrm{M} \text { device, Data Input GmbH } \\
\text { Whole-body } \\
\text { Right Side } \\
50 \mathrm{kHz}\end{array}$ & $\begin{array}{l}\text { The difference in PhA between the two groups was not significant In indvidual assessment, the highest PhA values were recorded in } \\
\text { the } T 1 \text { team }\end{array}$ \\
\hline $\begin{array}{l}\text { Levi Micheli } \\
2011 \\
\text { Original Article }\end{array}$ & $\begin{array}{l}\text { Italy (N-125 males) } \\
\text { Adolescents } \\
\text { Under } 17 \text { yrs }\end{array}$ & $\begin{array}{c}\text { Soccer } \\
\text { Medum-High Level }\end{array}$ & $\begin{array}{l}\text { About } 1 \text { monith after the begiming of the } \\
\text { regular seaso (october) }\end{array}$ & $\begin{array}{l}\text { BLA } 101 \text { Anniversary, Akert } \\
\text { Whole-bady } \\
\text { NR } \\
50 \mathrm{kHz}\end{array}$ & PhA and anthroponteric values were not correlated with athlecic performance. \\
\hline $\begin{array}{c}\text { Levi Micheli } \\
2014 \\
\text { Orignal Article }\end{array}$ & 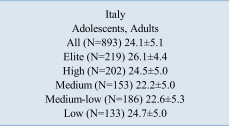 & 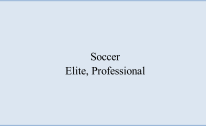 & $\begin{array}{l}\text { Before a midweek training session in the first } \\
\text { half of the insesason }\end{array}$ & $\begin{array}{l}\text { BIA-101, Akem/RL } \\
\text { Systems } \\
\text { Whole-body } \\
\text { Right Side } \\
50 \mathrm{kHz}\end{array}$ & An increased PhA in clite-level players was observed \\
\hline $\begin{array}{c}\text { Koury } \\
2014 \\
\text { Original Article }\end{array}$ & $\begin{array}{l}\text { Brazil }(\mathrm{N}-195 \text { males) } \\
\text { Adolescents }(\mathrm{N}-105) \text { 15.172.1 } \\
\text { Adults }(\mathrm{N}=90) 28.977 .3\end{array}$ & 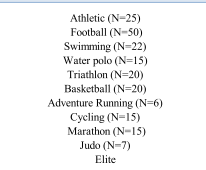 & $\begin{array}{l}\text { In resting condition afte } 24 \text { hours without } \\
\text { tranining }\end{array}$ & $\begin{array}{l}\text { RJL101 Quantum } \\
\text { BL-1010 } \\
\text { Whole-body } \\
\text { Right Side } \\
50 \mathrm{kHz}\end{array}$ & 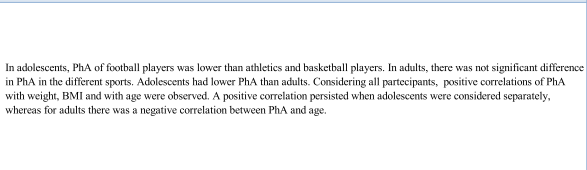 \\
\hline $\begin{array}{c}\text { Galanti } \\
2015 \\
\text { Orignal A Aricle }\end{array}$ & 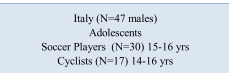 & $\begin{array}{l}\text { Soceer }(\mathbb{N}-30) \\
\text { Cyclism }(\mathbb{N}-17) \\
\text { Ehite }\end{array}$ & During he sports season & 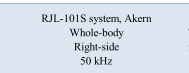 & 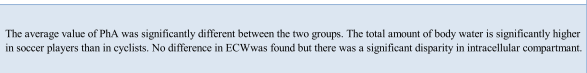 \\
\hline $\begin{array}{c}\text { Mali } \\
2015 \\
\text { Original Article }\end{array}$ & 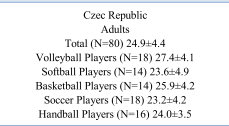 & $\begin{array}{l}\text { Vollcyball }(\mathrm{N}=18) \\
\text { Softball }(\mathrm{N}=14) \\
\text { Basketball }(\mathrm{N}=14) \\
\text { Socere }(\mathrm{N}-18) \\
\text { Handball }(\mathrm{N}=16) \\
\text { Elite }\end{array}$ & 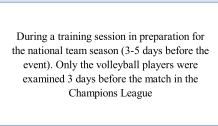 & $\begin{array}{l}\text { BIA } 2000 \text { M device, Data Trnut GmbH } \\
\text { Whole-body } \\
\text { NR }\end{array}$ & There were sigenificant differences in body composition but not in PhA between roups. \\
\hline $\begin{array}{c}\text { Mala } \\
2017 \\
\text { Orignal AAricle }\end{array}$ & $\begin{array}{l}\text { Czec Republic }(\mathbb{N}-59 \text { males and fermales }) \\
\text { Adolescents } \\
\text { Boys }(N-39) 12.11 .5 \\
\text { Girls }(N=20) 12.411 .4\end{array}$ & $\begin{array}{c}\text { Judo } \\
\text { Competive }\end{array}$ & $\mathrm{NR}$ & $\begin{array}{l}\text { Tanita MC-980MA } \\
\text { Whole-body } \\
\text { NR } \\
\text { Mully-frequency }\end{array}$ & 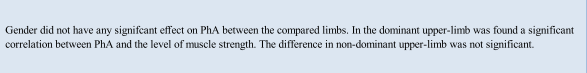 \\
\hline $\begin{array}{c}\text { Vetitia } \\
2017 \\
\text { Orignal Arricle }\end{array}$ & 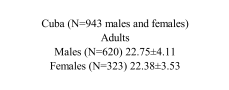 & $\begin{array}{c}\text { Dififerent sports } \\
\text { Elite }\end{array}$ & NR & $\begin{array}{c}\text { mBCA } 514 / 415 \text { Seca } 514 / 515 \mathrm{GmbH} \\
\& \text { Co } \\
\text { Whole-body } \\
N R \\
\text { Multy-frequency }\end{array}$ & 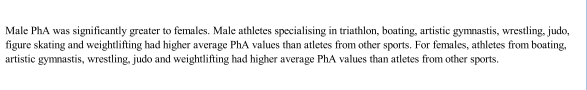 \\
\hline $\begin{array}{c}\text { Koury } \\
2018 \\
\text { Orignal Article }\end{array}$ & $\begin{array}{l}\text { Brazil (N-40 males) } \\
\text { Adolescents } \\
13.4+0.6\end{array}$ & $\begin{array}{c}\text { Soccer } \\
\text { Competitive }\end{array}$ & $\mathrm{NR}$ & 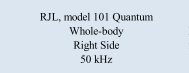 & 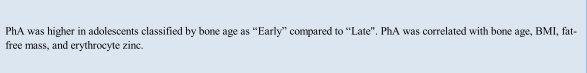 \\
\hline $\begin{array}{c}\text { Giurgi } \\
\text { 2018 } \\
\text { Orignal Article }\end{array}$ & $\begin{array}{l}\text { Italy (N-525 males) } \\
\text { Adults } \\
30.1 \pm 11.3\end{array}$ & $\begin{array}{l}\text { Cyclism } \\
\text { Professional, ,itt, young litc and amatour }\end{array}$ & At the time of their opinal performance level & $\begin{array}{c}\text { BLA-101, Akem/RrL } \\
\text { Systems } \\
\text { Wholebody } \\
\text { Dominant Side } \\
50 \mathrm{kHz}\end{array}$ & 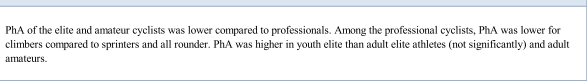 \\
\hline $\begin{array}{c}\text { Mara } \\
2018 \\
\text { Conference Paper }\end{array}$ & 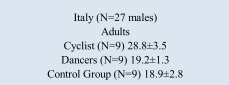 & $\begin{array}{l}\text { Cyclism (N-9) } \\
\text { Dance (N-9) } \\
\text { Professional }\end{array}$ & During he sports season & 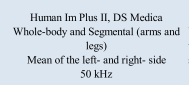 & 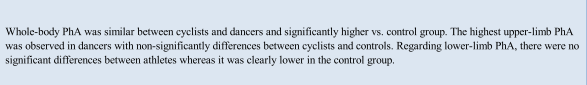 \\
\hline $\begin{array}{c}\substack{\text { Mara } \\
2018 \\
\text { Conference Paper }} \\
\text { (n) }\end{array}$ & 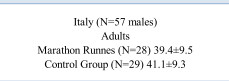 & $\begin{array}{l}\text { Marathon Rumpers (N-28) } \\
\text { Profefsional }\end{array}$ & $\mathrm{NR}$ & 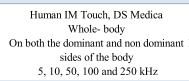 & I Murathon nunners had a siginifcannly higher PhA han heallhy control subjects. \\
\hline$\underset{\substack{\text { Marini } \\
2019 \\
\text { Orignal Article }}}{n}$ & $\begin{array}{l}\text { Portugal (N-202 males and females) } \\
\text { Adolescents, Adults } \\
\text { Males }(\mathrm{N}=13921.51 .50 \\
\text { Females }(\mathrm{N}=323) \\
\text { 20.75.5.1 }\end{array}$ & 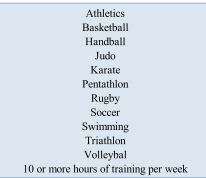 & During the in-session period & 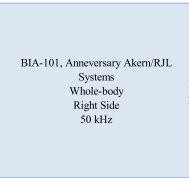 & $\begin{array}{l}\text { Mean PhA was highte in males than femules. In boht sexes PhA was negatively correlated with the ECWICW ratio, while there is a } \\
\text { positive association with ICW. }\end{array}$ \\
\hline
\end{tabular}


Table 2 Descriptive characteristics of longitudinal included studies $(n=14)$

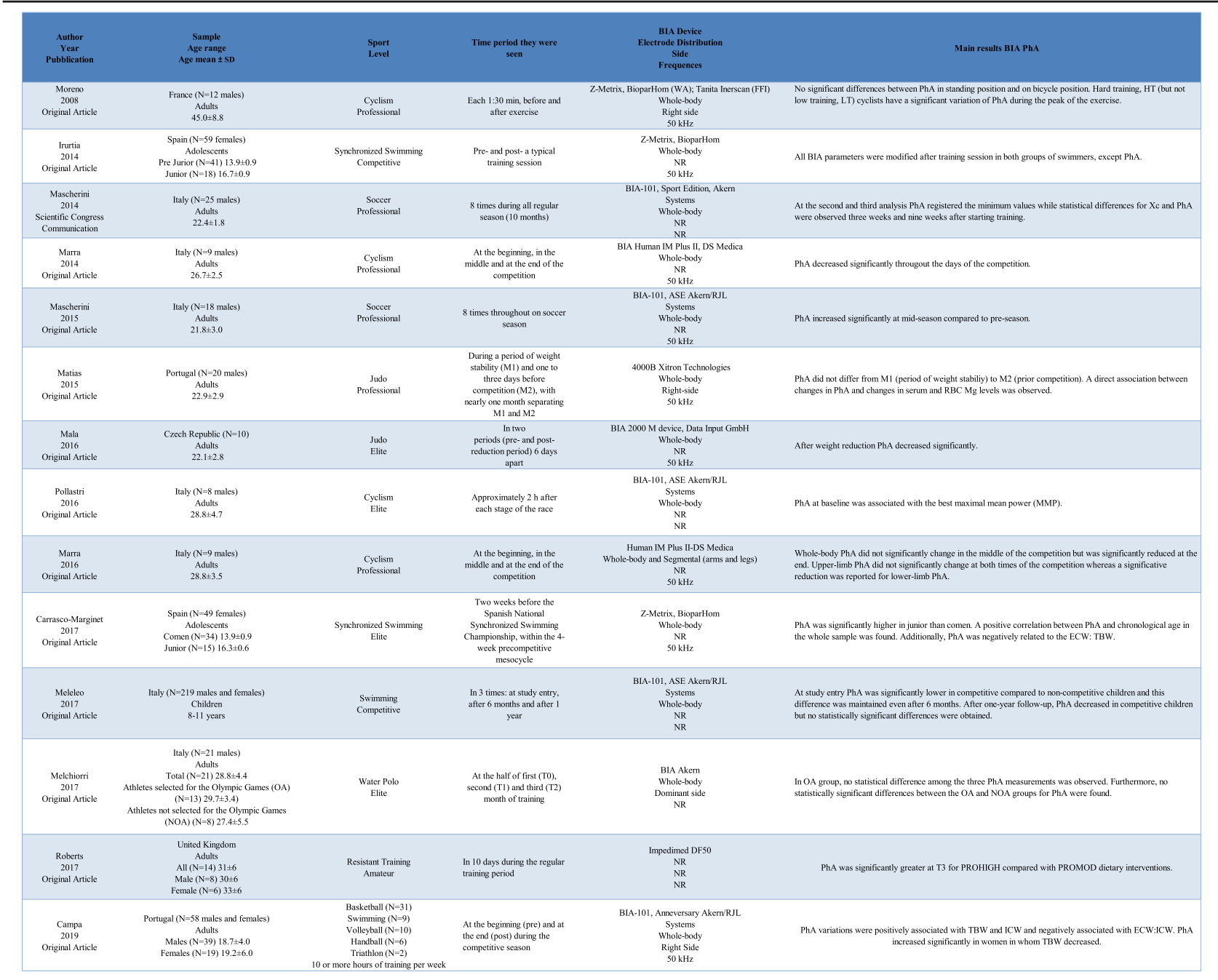

angle was measured at $50 \mathrm{kHz}$. Piccoli et al. [13], with BIS methodology, measure $\mathrm{PhA}$ at 5 and $50 \mathrm{kHz}$ assuming that the current path is only extracellular at the lowest frequencies and that is both extra- and intracellular at the highest frequencies. Authors in fourteen papers performed BIA and BIVA. Other information is available in in Table 1 and Table 2.

\section{Risk of bias}

Sample size was small especially in longitudinal studies (Table 2). Measurement conditions of BIA were sometimes not completely described. Furthermore, the time period in which patients were included in the studies was not always clearly described.

The risk of overall bias was moderate to high. Three of the observational studies had an overall good rating in terms of quality, while sixteen were rated as fair and two as poor. Only two of the before-after (pre-post) studies had an overall good rating in terms of quality, eight were rated as fair and four as poor (Additional file 1: Table S1).

\section{Cross-sectional studies \\ Differences between athletes and controls}

Six studies have compared $\mathrm{PhA}$ in athletes and controls.

In the paper by Piccoli et al. [13], professional male bodybuilders $(n=30,31.2 \pm 5.7 \mathrm{yrs})$ had a higher PhA (+ $17.8 \%$ at $50 \mathrm{kHz}$ ) than control subjects. This finding suggested more cell membranes per fluid volume unit, i.e. increased intracellular water and BCM.

In the same year, D'Alessandro et al. [15] found that female rhythmic gymnasts $(n=55,15.2 \pm 2.2 \mathrm{yrs})$ had $\mathrm{PhA}$ values within the normal range for age and sex. No direct comparison with a control group was reported.

Later, Marra et al. [16] showed that female ballet dancers ( $n=15,18.9 \pm 1.7 \mathrm{yrs}$ ) had significantly higher PhA compared to controls, not only for the whole body 
$(+9.6 \%)$ but also for upper limbs $(+22.2 \%)$ and lower limbs $(+10.0 \%)$.

Meleleo et al. [17] studied two groups of children: competitive individuals attending swimming and gymnastics sports clubs $(n=29,8.0-10.5$ yrs $)$ vs. a control group of age-matched healthy children $(n=190,8.2-$ 10.5 yrs). At study entry PhA was significantly lower in competitive vs. non-competitive children and this difference was maintained even after 6 months. After one-year follow-up, PhA decreased in competitive children but no statistically significant differences were obtained.

Recently, Marra et al. [18] evaluated 27 young males: 9 cyclists $(28.8 \pm 3.5 \mathrm{yrs}), 9$ dancers $(19.2 \pm 1.3 \mathrm{yrs})$ and 9 young control normal-weight men $(18.9 \pm 2.8 \mathrm{yrs})$. Data of cyclists were collected during a three-week stage race, while dancers were studied during the ballet season. Whole-body $\mathrm{PhA}$ was similar between cyclists and dancers being significantly higher vs. controls $(+11.4 \%$ and $+12.0 \%)$. The highest upper limb PhA was observed in dancers with non-significantly differences between cyclists and controls. Lower-limb PhA is similar in cyclists and dancers but lower in the control group $(-15.4 \%)$.

In another paper the same authors [19] studied 28 male marathon runners (personal best in the last year < $195 \mathrm{~min} ; 39.4 \pm 9.5 \mathrm{yrs}$ ) and 29 male control subjects with aerobic physical activity $<60 \mathrm{~min} /$ week. A significant difference between groups emerged (PhA $+9.7 \%$ in marathon runners).

\section{Differences between genders}

Differences in PhA between genders were consistently evaluated in three studies.

Veitia et al. [20] performed BIA in 943 Cuban athletes (620 males, $22.8 \pm 4.1$ yrs., and 323 females $22.4 \pm 3.5$ yrs) specialized in 26 different sports. Mean PhA value was significantly higher $(+15.5 \%)$ in males than females, with a difference for most of the sports considered.

The same year, Mala et al. [21] assessing whole-body BIA variables in adolescent judo athletes (39 males, $12.1 \pm 1.5$ yrs., and 20 females, $12.4 \pm 1.4$ yrs) members of the Czech cadet and junior teams, observed that gender did not have a significant effect on PhA and that there was no difference between the dominant or nondominant body sides.

Lastly, in the recent study by Marini et al. [10] on 202 athletes involved in 11 different sports mean PhA was definitely higher in males than females $(+13.2 \%)$. No data were available for males and females practicing the same sport.

\section{Differences due to age}

$\mathrm{PhA}$ in athletes of various age were determined in five studies.
Torres et al. [22] studied 158 elite athletes (13-48 yrs) practicing adventure running, cycling, judo, longdistance running, short-distance running, soccer, swimming, triathlon and water polo. PhA was lower in adolescents (10-19 years) than in young adults (20-29 years), and increased with age within the same specialty (soccer). The highest mean value was observed in the third decade of life. In the athletes aged 10-19 years, $57 \%$ of $\mathrm{PhA}$ values were lower than the 5 th reference percentile (6) whereas in the other three age groups the corresponding values were $2 \%, 0 \%$ and $0 \%$ respectively.

Mala et al. [23] evaluated PhA in three teams of female national volleyball players: a senior national team (SNT, $n=12,24.0 \pm 1.1 \mathrm{yrs}$ ), a junior national team (under 19, $\mathrm{n}=12,18.0 \pm 0.6 \mathrm{yrs}$ ), and a youth national team (under $17, n=14,16.6 \pm 0.5 \mathrm{yrs}$ ). SNT and U17 players were evaluated 3 weeks before the European Championship 2008 whereas U19 players were studied 2 weeks before qualification at European Championship 2008. The highest PhA values were recorded in the SNT group, with a significant difference between SNT and Under 19 players.

In the study by Koury et al. [24] on male adolescent ( $n=105,15.1 \pm 2.1 \mathrm{yrs})$ and adult $(n=90,28.9 \pm 7.3 \mathrm{yrs})$ athletes, considering several sport groups (athletics, football, swimming, water polo, triathlon, basketball, adventure running, cycling, marathon and judo), adolescent athletes showed lower PhA than adult athletes (-15.9\%). $\mathrm{PhA}$ in the adolescents remained lower when sport type was used as a covariate in a multivariate general linear model $(p<0.001)$. A positive correlation between $\mathrm{PhA}$ and age was observed in adolescents, whereas adult athletes exhibited a negative correlation. The influence of age on PhA persisted when controlled for sport type.

More recently, Carrasco-Marginet et al. [25] evaluated young female elite synchronized swimmers of two age categories (34 comen, $13.9 \pm 0.9$ yrs., and 15 junior, $16.3 \pm 0.6 \mathrm{yrs})$ performing a single long, high-intensity training session. They found that $\mathrm{PhA}$ was significantly higher in junior $(+7.1 \%)$ than comen, with a positive correlation between $\mathrm{PhA}$ and age.

Finally, Giorgi et al. [26] reported that in 525 male road cyclists $(30.1 \pm 11.3 \mathrm{yrs}) \mathrm{PhA}$ values were higher (not significantly) in youth elite compared to adult elite athletes or adult amateurs.

\section{Comparisons between different sport disciplines}

Five studies compared PhA between athletes practicing different sports.

Kim et al. [27], in a conference paper, showed that PhA was higher in 6 female gymnasts $(20.8 \pm 0.8$ yrs., PhA $5.9 \pm 0.5$ degrees) than 10 female dancers $(20.7 \pm$ 0.7 yrs., PhA $5.0 \pm 0.3$ degrees).

In the paper by Koury et al. (see above) [24], differences in PhA between various sports were evaluated. 
Adolescent football players had a lower mean value than track and field athletes $(-31.7 \%)$ or basketball players ($15.3 \%)$, An overall significant difference was observed between adult athletes practicing athletics, swimming, triathlon, water polo, adventure running, cycling, marathon and judo but no pairwise comparisons were performed. Of note, sample size was small in most experimental groups (even $<10$ subjects).

Galanti et al. [28] in male adolescents observed that the average value of PhA was slightly but significantly higher (7.3 \pm 0.6 vs. $7.1 \pm 0.5$ degrees $)$ in cyclists $(n=17$, $14-16$ yrs) than soccer players $(n=30,15-16$ yrs).

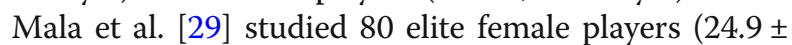
4.4 yrs) of five team sports (volleyball, softball, basketball, soccer and handball). They observed significant differences in body composition between groups (for instance, with respect to FFM), but did not detect any significant differences in PhA. The variability of PhA was high in all groups, as indicated by the large standard deviation values.

In their large study, Veitia et al. (see above) [20] studied 943 subjects which made up the Cuban adult national selection in 26 sports. In males, athletes practicing triathlon, weight lifting, boating, artistic gymnastics and wrestling had average values of $\mathrm{PhA} \geq 7$ degrees that were higher compared to those of other athletes. In females, athletes from boating, artistic gymnastics and weight lifting had higher average values of $\mathrm{PhA}$ ( $\geq 6.5$ degrees) than athletes from other sports.

\section{Comparisons within the same sport discipline}

Three studies evaluated the possible variation of $\mathrm{PhA}$ due to different performance levels. Maly et al. [30] studied two volleyball teams $(n=12,24.3 \pm 2.7$ yrs., and $n=9$, $20.8 \pm 2.1 \mathrm{yrs})$, participating in the CEV Champion League 2008-2009. The first team did not pass beyond the basic round, whereas the second one participated in the quarterfinal round. There was no significant difference in mean PhA between the two teams.

In the study by Levi Micheli et al. [31] 893 male soccer players $(24.1 \pm 5.1 \mathrm{yrs})$ were subdivided in five groups according to performance level (i.e. the division in which the team plays). An increased PhA was observed in the elite-level group compared to the other groups (high-level, medium-level, medium-low level and low-level).

Finally, Giorgi et al. (see above) [26] reported that PhA of elite $(n=79,21.1 \pm 2.9 \mathrm{yrs})$ and amateur cyclists $(n=$ $232,39.0 \pm 10.5 \mathrm{yrs}$ ) (but not that of youth elite cyclists, $n=59,16.8 \pm 1.1 \mathrm{yrs})$ was lower $(p<0.05)$ in comparison to professionals ( $n=155,26.3 \pm 4.7 \mathrm{yrs})$. Among these latter PhA was lower for climbers compared to sprinters and all-rounders $(p<0.05)$.

\section{Differences due to racial and genetic profile}

In the only study reporting data on racial profile, Hortobagyi et al. [32] showed that mean PhA was higher in 55 black (19.4 \pm 1.2 yrs) compared to 35 white $(19.7 \pm 1.5$ yrs) Division I American Football players.

Levi Micheli et al. [33] determined the genetic profile in a group of young adolescent Italian medium to highlevel soccer players $(<17 \mathrm{yrs})$ assessing the distribution of ACE genotypes (DD, ID, II) and VDR gene (FF, Ff and $\mathrm{ff}$ ) polymorphisms, because of their association with performance-related functions. They assessed body composition with BIA and studied the athletic performance by standard functional performance field tests (squat jump, countermovement jump, 10- and 20-m sprint time). Concerning ACE genotypes, PhA was higher in athletes harboring the $\mathrm{D}$ allele. Furthermore, regarding VDR gene, the FF genotype was associated with a mean $\mathrm{PhA}$ higher than that observed with FF and ff genotypes.

\section{Correlation with other variables}

Seven studies have evaluated the relationships between $\mathrm{PhA}$ and other variables.

In the study by Torres et al. [22] (see above) PhA was positively correlated with BMI $(\mathrm{r}=0.66 ; p<.001)$. Similarly, Koury et al. (see above) [24] observed a positive association with both weight and BMI $(r=0.498$ and 0.583 , respectively, $p<0.01$ ).

Ney et al. [34] studied 20 male short-distance swimmers (18.1 \pm 4.1 yrs., 50 and $100 \mathrm{~m}$ freestyle) and found significant correlations of PhA with fatty acid and tocopherol composition in plasma and erythrocytes membranes. PhA was positively related $(\mathrm{r}=0.51, p=0.024)$ with erythrocyte 22:5 n-3 (an index of DHA deficiency). On the contrary, PhA was neither associated with other erythrocyte PUFAs, nor with indices of PUFA and DHA status, or erythrocyte tocopherols.

Levi Micheli et al. (see above) [33] claimed that in a well-trained population, $\mathrm{PhA}$ and anthropometric values were not correlated with athletic performance.

In the abovementioned study by Mala et al. [21] in judo adolescent athletes a significant correlation emerged between PhA and handgrip strength (boys: $\mathrm{r}=0.64, p<0.01$, girls: $\mathrm{r}=0.61, \mathrm{p}<0.01$ ) for the dominant limb.

In a recent study Koury et al. [35] evaluated the relation between minerals and PhA. It was found that in 40 adolescent male soccer athletes $(13.4 \pm 0.6 \mathrm{yrs}), \mathrm{PhA}$ tended $(p=0.010)$ to be higher in adolescents classified by bone age as "Early" compared to "Late". PhA also correlated $(p<0.05)$ with bone age $(\mathrm{r}=0.562)$, BMI $(\mathrm{r}=$ $0.382)$, FFM $(r=0.468)$ and erythrocyte zinc concentration $(r=0.379)$. PhA was higher in adolescents with erythrocyte zinc concentration above the median than those below the median. Multiple linear regression analysis revealed that bone age $(p=0.001)$ and erythrocyte 
zinc concentration $(p=0.047)$ were both positive predictors of $\mathrm{PhA}$.

In a relevant cross-sectional study in 202 athletes, Marini et al. [10] showed that in both males and females $\mathrm{PhA}$ was negatively correlated with the $\mathrm{ECW} / \mathrm{ICW}$ ratio (males: $\mathrm{r}=-0.493, p<0.001$; females: $\mathrm{r}=-0.408, p<$ $0.001)$, while there was a positive association with ICW (males: $\mathrm{r}=0.327, \mathrm{p}<0.001$; females: $\mathrm{r}=0.243, p=0.080$ ).

\section{Short-term studies and longitudinal studies}

Only three papers evaluated changes in PhA immediately before and after a training session. In two of the three short-term studies $[36,37]$ there were no details regarding intensity and/or volume of the exercise session probably due to the study type (conference papers).

Moreno et al. [36] showed that in 12 male cyclists $(45.0 \pm 8.8 \mathrm{yrs})$ there was a non-significant difference between PhA during $30 \mathrm{~min}$ of exercise in standing position and on bicycle position. Hard training cyclists exhibited significant $\mathrm{PhA}$ changes at exercise peak, but this was not the case for the low training cyclists. Peaks correspond to maximal heart rate.

In another conference paper, junior $(n=18,16.7 \pm 0.9$ yrs) and pre-junior $(n=41,13.9 \pm 0.9$ yrs $)$ female synchronized swimmers were studied by Irurtia et al. [37]. All BIA parameters, except PhA, in both groups varied after training session.

More recently, Carrasco-Marginet et al. [25] (see above) observed a significantly increased PhA between pre and post-training $(p<0.05)$ in both junior $(208.4 \pm 10.3 \mathrm{~min}$ of training with $6.8 \pm 0.6$ rating of perceived exertion, following the RPE scale) and comen $(149.6 \pm 3.3 \mathrm{~min}$ of training with $6.4 \pm 0.5$ of RPE) elite synchronized swimmers. PhA was negatively related to BIA-derived ECW/TBW ratio. No correlations were observed between bioelectrical pre to post changes in relation to BM.

Eleven papers have evaluated changes in $\mathrm{PhA}$ with time due to training programmes and/or other planned interventions.

Mascherini et al. [38] reported data on 11 professional male soccer players $(22.4 \pm 1.8 \mathrm{yrs})$ measuring their PhA eight times during regular season. Mean PhA was significantly lower than baseline 3 weeks and 9 weeks after starting training. Later, in 18 professional italian soccer players $(21.8 \pm 3.0 \mathrm{yrs})$ the same authors [39] found that PhA increased significantly at mid-season compared to pre-season $(p<0.05)$.

Marra et al. [40] evaluated whole-body PhA in professional cyclists $(n=9,26.7 \pm 2.5 \mathrm{yrs})$ participating in a 3week stage race. They collected data at the beginning (the day before the race), halfway through (rest day, after the 9th lap) and at the end of the race (the last day, after the 20th lap). PhA was significantly decreased halfway through $(\Delta=-0.51 \pm 0.45, p<0.001)$ and at the end of the race $(\Delta=-1.00 \pm 0.27, \mathrm{p}<0.001)$. The same authors [41] assessed segmental BIA in a group of professional cyclists (n. 9, $28.8 \pm 3.5 \mathrm{yrs)}$ participating in a multiplestage bicycle race. Whole-body PhA did not significantly change after the first half of the race but significantly decreased at the end $(p<0.05)$. Upper-limb PhA did not significantly change whereas a significant reduction was reported for lower-limb PhA.

A study of Pollastri [42] on 8 elite cyclists $(28.8 \pm 4.7$ yrs) investigated whether body water changes during a multiple-stage bicycle race affected the average maximal mean power (MMP) of different time durations. PhA at baseline was associated with the best MMP over $15 \mathrm{~s}$ as observed during competition (20 measurements).

Matias et al. [14] in 20 male judo athletes $(22.9 \pm 2.9$ yrs) observed that PhA did not differ from a period of weight stability to prior competition; mean change in weight was $-0.8 \pm 2.2 \mathrm{~kg}$. There was a positive association between changes in $\mathrm{PhA}$ and those in serum and RBC Mg levels.

Meleleo et al. [17] studied two groups of children: competitive subjects attending swimming and gymnastics sports clubs ( $n=29,8.0-10.5 \mathrm{yrs})$ and 'control' agematched healthy children ( $n=190,8.2-10.5 \mathrm{yrs})$. At baseline PhA was significantly lower in competitive subjects and this difference was maintained even after 6 months. After one-year follow-up, PhA decreased, but not significantly, in competitive children.

Mala et al. [43] studied 10 elite youth judo athletes $(22.1 \pm 2.8 \mathrm{yrs})$ before and after pre-competitive weight loss (6 day on average, using dehydration). BIA was performed before and after the weight reduction period, 6 days apart. Mean PhA significantly decreased after weight loss $(-4.1 \%, p<0.01)$.

In the study of Melchiorri et al. [44], 21 male elite water polo athletes intensively trained based on a detailed program for 3 months before the Olympic Games. Only 13 athletes (OA, $29.7 \pm 3.4 \mathrm{yrs}$ ) participated to the Olympics Games, 8 were excluded (NOA, 27.4 \pm 5.5 yrs). PhA was evaluated after the first (T0), second (T1) and third (T2) month of training. There was no statistical difference among the three measurements for PhA in the OA group. Furthermore, data showed no statistically significant differences of PhA between the OA and NOA groups.

Campa et al. [45] performed BIA in 58 athletes at baseline and after 6 months during the competitive season. PhA variations were positively associated with TBW and ICW and negatively associated with the ECW/ICW ratio.

Finally, although not concerning athletes, we considered Roberts's study [46] because it gave some information on the effects of protein supplementation plus physical activity on phase angle. This is an interesting 
topic for future research on sport nutrition. The authors studied the effects of a resistance training programme (at least $3 \mathrm{~h} /$ week) in 14 resistance-trained individuals $(8$ males $30 \pm 6$ yrs.; 6 females $33 \pm 6$ yrs). They underwent two 10-day isocaloric dietary regimes with a protein con-

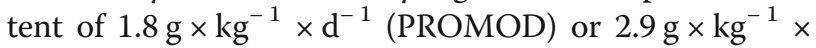
$\mathrm{d}^{-1}$ (PROHIGH). On days 8-10 (T1-T3), participants undertook resistance exercise under controlled conditions, performing 3 sets of squats, bench press and bentover rows at $80 \% 1$ repetition maximum until volitional exhaustion. In PROHIGH group PhA increased at T3 compared to $\mathrm{T} 1$ and $\mathrm{T} 2$, while it tended to decrease in the PROHIGH group, although not significantly. PhA was slightly higher at T3 for PROHIGH $(+2.2 \%)$ compared with PROMOD $(p=0.012)$.

\section{Discussion}

BIA is applied in athletes as a field technique to estimate body composition, being useful in sport science for single measurements or for tracking body composition changes [7]. On the other hand, raw BIA variables, such as $\mathrm{PhA}$ or IR, are commonly related to $\mathrm{ECW} / \mathrm{ICW}$ ratio, $\mathrm{BCM}$, and cellular integrity [2]. In addition, an association between muscle strength and PhA has been observed in various pathophysiological conditions (for instance,1-3), suggesting that raw BIA may be useful in assessing muscle quality.

In this context, only a few papers have so far evaluated raw BIA variables in athletes. A recent systematic review examined the applications of BIVA in sports and exercise, a methodology giving information on hydration status by analyzing the length of bioimpedance vector and its inclination [9]. The authors concluded that the current technique, called "classical BIVA", is not fully reliable to identify dehydration in individual athletes. The review by Custodio Martins et al. [47] explored the use of different BIA-derived estimates of body composition in athletes, adding a concise, preliminary view on $\mathrm{PhA}$, a raw BIA variable that has been considered in recent years for assessing body composition in various pathophysiological conditions [1-3].

In this systematic review, we aimed to extend previous information on $\mathrm{PhA}$ values as measured in athletes by focusing in depth on different issues of interest. Thirtyfive papers were selected according to inclusion and exclusion criteria. In almost all cases single-frequency BIA has been performed (on the whole body). Although it is well known the standardization of measurement conditions is essential for obtaining accurate and reproducible BIA data, most of selected studies did not give enough details in this respect, in particular on the length of time since the last training session (a critical aspect especially in the case of strenuous exercise).

One might expect that training, especially muscle strengthening, should affect not only muscle function but also BCM and muscle cell mass. The first question in this study sought to determine whether PhA differs between athletes and control subjects. Surprisingly, only few papers have so far addressed this issue, sometimes in small groups of athletes. A very marked increase in PhA was observed in bodybuilders [13] $(+17.8 \%$ on the average), female dancers [16] $(+9.6 \%)$, male dancers [18] $(+12.0 \%)$, cyclists [18] $(+$ $11.4 \%)$ and marathon runners [19] (+ 9.7\%).

Thus, these findings suggest that muscle strengthening causes a greater increase in PhA compared to endurance training. Indeed, contrary to expectations, Meleleo et al. [17] reported that PhA was significantly lower in competitive vs. non-competitive children, suggesting that the effects of training on PhA may be different in childhood.

As far as main individual's characteristics are concerned, in the general population PhA increases with age in both genders until late adulthood and then decrease in the elderly [22-26], with a between-gender difference that becomes greater through adolescence $[48,49]$ and with mean values in adult age consistently higher in males than females $[5,6]$.

The papers selected for gender diversity are in line with the aforementioned findings, with no difference in young adolescent judo athletes [21] and significant higher values in adolescent/adult male compared to female athletes [20]. Similarly, four out of five selected papers reported an age trend in various sports [22-25], whereas a single paper found the opposite, with higher PhA in adolescent male than adult male road cyclists [26]. It should be noted that differences in years of practice and training programmes may influence changes with time.

A key point of the present review was to evaluate whether and to what extent PhA differs between different sports and performance levels. Overall, the selected papers have provided inconsistent and puzzling findings, possibly because of inappropriate study design (for instance, in selecting subjects) or small sample sizes. The variability of $\mathrm{PhA}$ was high, as indicated by large standard deviation values [27-29]. Variations between sports emerge but no definite conclusions could be drawn on endurance vs. resistance training or recreational vs. competitive sports, although some results suggest indirectly that $\mathrm{PhA}$ increase with muscle-strengthening activities [20].

Turning to athletes of the same sport, two studies [26, 31] demonstrated that $\mathrm{PhA}$ was higher in soccer players and cyclists with a better performance level, whereas another one did not find differences between a stronger and a weaker volleyball teams [30]. Thus, it could be argued (but not definitely demonstrated), that the relationships between PhA and performance level may vary in different sports and are possibly influenced by the criteria used to assess performance level. Interestingly, changes emerge also for the same sport when athletes differ depending on their physical characteristics. For 
instance, among cyclists PhA was lower for climbers compared to sprinters and all-rounders [26].

Overall, in order to interpret variability of $\mathrm{PhA}$, a single study [33] indicated that PhA is influenced by ACE or VDR gene polymorphisms, in line with their involvement in a variety of performance-related functions. In addition, another study has shown that mean PhA was higher in white than black football players [32], which may not surprising given that differences in body composition due to ethnicity are well known [50].

Finally, longitudinal evaluation of body composition may offer, at least in theory, relevant information on the changes in body composition and hydration due to training or untraining, which might be associated with physical performance. Unfortunately, the papers selected for the present review [14, 17, 25, 36-46] have given inconsistent results. A comprehensive view of the issue cannot be formed because they considered different athletic disciplines and had very different experimental protocols (sometimes with small experimental groups).

\section{Conclusions}

This systematic review aimed to summarise the current knowledge on the evaluation of BIA-derived PhA in athletes. Of note, two recent studies strongly support the idea that $\mathrm{PhA}$ is an index of $\mathrm{ECW} / \mathrm{ICW}$ ratio or $\mathrm{BCM}$ $[10,45]$. PhA increases with age and is likely to be higher in males. Unfortunately, it is still uncertain to what extent PhA varies between different sports and changes with training/untraining. It can be argued that for a given sport much more data should be collected in a systematic way and for a period of time appropriate in order to determine changes and trends. This is even more crucial in the case of intervention studies.

From a practical point of view, at the present time the measurement of PhA is a promising approach to evaluate muscle quality in groups of athletes, for instance detrained compared to well-trained subjects. On the other hand, further studies are needed to specify the most appropriate measurement conditions and to assess to what extent PhA may be a reliable index for identifying individual's characteristics critical to performance, evaluating the effects of training programs, managing weight strategies in weight-category sports, etc.

\section{Supplementary information}

Supplementary information accompanies this paper at https://doi.org/10. 1186/s12970-019-0319-2.

Additional file 1: Table S1. Quality Assessment Tool for Observational Cohort and Cross-Sectional Studies. Table S2. Quality Assessment Tool for Observational Cohort and Cross-Sectional Studies (Longitudinal Studies). Table S3. Quality Assessment Tool for Before-After (Pre-Post) Studies With No Control Group. Risk of bias scores of included studies.

\section{Abbreviations}

BCM: Body Cell Mass; BIA: Bioelectrical Impedance Analysis; BIS: Bioelectrical Impedance Spectroscopy; BIVA: Bioelectrical Impedance Vector Analysis; ECW: Extracellular Water; FFM: Fat-Free Mass; FM: Fat Mass; ICW: Intracellular Water; IR: Impedance Ratio; PhA: Phase Angle; R: Resistance; TBW: Total Body Water; Xc: Reactance; Z: Impedance

\section{Acknowledgements}

Not applicable.

\section{Authors' contributions}

LS, MM, and ODV conceived the review. ODV and LS undertook the literature search, data extraction, and drafted the report. MM assisted in interpretation of results and was involved in the critical revision of report. All authors read and approved the final manuscript.

\section{Funding}

Not applicable.

\section{Availability of data and materials}

All data pertaining to the conclusions of the study are found within the article. The corresponding data set used is available under reasonable requests.

Ethics approval and consent to participate

Not applicable.

\section{Consent for publication}

Not applicable.

\section{Competing interests}

The authors declare that they have no competing interests.

\section{Author details}

${ }^{1}$ Department of Clinical Medicine and Surgery, Federico II University Hospital, Via S. Pansini 5, 80138 Naples, Italy. ${ }^{2}$ Department of Public Health, School of Medicine, Federico II University, Naples, Italy.

Received: 18 July 2019 Accepted: 16 October 2019

Published online: 06 November 2019

\section{References}

1. Norman K, Stobäus N, Pirlich M, Bosy-Westphal A. Bioelectrical phase angle and impedance vector analysis - clinical relevance and applicability of impedance parameters. Clin Nutr. 2012;31(6):854-61.

2. Lukaski HC, Kyle UG, Kondrup J. Assessment of adult malnutrition and prognosis with bioelectrical impedance analysis : phase angle and impedance ratio. Curr Opin Clin Nutr Metab Care. 2017:20:1-10.

3. de Blasio F, Santaniello MG, de Blasio F, Mazzarella G, Bianco A, Lionetti L, et al. Raw BIA variables are predictors of muscle strength in patients with chronic obstructive pulmonary disease. Eur J Clin Nutr. 2017;71(11):13361340. https://doi.org/10.1038/ejcn.2017.147.

4. Mundstock E, Azambuja Amaral, Marina Baptista RR, Sarria EE, Grecco dos Santos RR, Detoni Filho A, Rodriguez CAS, et al. Association between phase angle from bioelectrical impedance analysis and level of physical activity: Systematic review and meta-analysis. Clin Nutr. 2019;38(4):1504-1510. https://doi.org/10.1016/j.clnu.2018.08.031.

5. Bosy-Westphal A, Danielzik S, Wiese S, Müller MJ, Later W, Dörhöfer R-P. Phase angle from bioelectrical impedance analysis: population reference values by age, sex, and body mass index. J Parenter Enter Nutr. 2008;30(4):309-16.

6. Barbosa-Silva MCG, Barros AJ, Wang J, Heymsfield SB, Pierson RN. Bioelectrical impedance analysis: population reference values for phase angle by age and sex. Am J Clin Nutr. 2018;82(1):49-52.

7. Moon JR. Body composition in athletes and sports nutrition: an examination of the bioimpedance analysis technique. Eur J Clin Nutr Nature Publishing Group. 2013:67(S1):S54-9.

8. Buffa R, Mereu E, Comandini O, Ibanez ME, Marini E. Bioelectrical impedance vector analysis (BIVA) for the assessment of two-compartment body composition. Eur J Clin Nutr Nature Publishing Group. 2014;68(11):1234-40.

9. Castizo-Olier J, Irurtia A, Carrasco-Marginet M. Bioelectrical impedance vector analysis (BIVA) in sport and exercise: Systematic review and future 
perspectives. PLoS One. 2018;13(6):e0197957. https://doi.org/10.1371/journal. pone.0197957.

10. Marini E, Campa F, Buffa R, Stagi S, Matias CN, Toselli S, et al. Phase angle and bioelectrical impedance vector analysis in the evaluation of body composition in athletes. Clin Nutr. 2019. https://doi.org/10.1016/j.clnu.2019.02.016.

11. Moher D, Liberati A, Tetzlaff J, Altman DG, Altman D, Antes G, et al. Preferred reporting items for systematic reviews and meta-analyses: the PRISMA statement. J Chinese Integr Med. 2009;7(9):889-96.

12. National Institution of Health: U. S Department of Health and Human Services. Quality assessment tool for observational cohort and crosssectional studies 2014

13. Piccoli A, Pastori G, Codognotto M, Paoli A. Equivalence of information from single frequency $\mathrm{v}$. bioimpedance spectroscopy in bodybuilders. Br J Nutr. 2007;97(1):182-92.

14. Matias CN, Monteiro CP, Santos DA, Martins F, Silva AM, Laires MJ, et al. Magnesium and phase angle: a prognostic tool for monitoring cellular integrity in judo athletes. Magnes Res. 2015;28(3):92-8.

15. D'Alessandro C, Morelli E, Evangelisti I, Fabio G, Franzoni F, Lazzeri D, et al. Profiling the diet and body composition of subelite adolescent rhythmic gymnasts. Pediatr Exerc Sci. 2016;19(2):215-27.

16. Marra M, Caldara A, Montagnese C, De Filippo E, Pasanisi F, Contaldo F, et al. Bioelectrical impedance phase angle in constitutionally lean females, ballet dancers and patients with anorexia nervosa. Eur J Clin Nutr Nature Publishing Group. 2009;63(7):905-8.

17. Meleleo D, Bartolomeo N, Cassano L, Nitti A, Susca G, Mastrototaro G, et al. Evaluation of body composition with bioimpedence. A comparison between athletic and non-athletic children. Eur J Sport Sci. 2017:17(6):710-9.

18. Marra M, Sammarco R, Speranza E, Di Vincenzo O, Morlino D, Cioffi I, Scalfi L, Pasanisi F. Body Composition and Segmental Phase Angle in Physically Active Men. In Proceedings of the 6th International Congress on Sport Sciences Research and Technology Support - Volume 1. 2018. p. 154-157. https://doi.org/10.5220/0007232101540157.

19. Marra M, Di Gregorio A, Alicante P, Di Vincenzo O, Sammarco R, Speranza E, et al. Evaluation of Body Composition in Competitive Male Marathon Runners. In Proceedings of the 6th International Congress on Sport Sciences Research and Technology Support - Volume 1. p. 158-160. https://doi.org/ 10.5220/0007232301580160.

20. Carvajal Veitia W, Deturnell Campo Y, Echavarría García IM, Aguilera Chavez D, Esposito Gutiérrez LR, Cordova A. Body composition analysis using bioelectrical parameters in the Cuban sporting population. Arch Med Deport. 2017;34(4):207-15.

21. Mala L, Maly T, Camilleri R, Dornowski M, Zahalka F, Petr M, et al. Gender differences in strength lateral asymmetries, limbs morphology and body composition in adolescent judo athletes. Arch Budo. 2017;13:377-85.

22. Torres AG, Oliveira KJF, Oliveira-Junior, Astrogildo V.Gonçalves MC, Koury JC. Biological determinants of phase angle among Brazilian elite athletes. Proc Nutr Soc. 2009;67(OCE8):2018

23. Malá L, Maly T, Záhalka F, Bunc V. The profile and comparison of body composition of elite female volleyball players. Kinesiology. 2010;42(1):90-7.

24. Koury JC, Trugo NMF, Torres AG. Phase angle and bioelectrical impedance vectors in adolescent and adult male athletes. Int I Sports Physiol Perform. 2014;9(5):798-804.

25. Carrasco-Marginet M, Castizo-Olier J, Rodríguez-Zamora L, Iglesias X, Rodríguez FA, Chaverri D, et al. Bioelectrical impedance vector analysis (BIVA) for measuring the hydration status in young elite synchronized swimmers. PLoS One. 2017;12(6):1-17.

26. Giorgi A, Vicini M, Pollastri L, Lombardi E, Magni E, Andreazzoli A, et al. Bioimpedance patterns and bioelectrical impedance vector analysis (BIVA) of road cyclists. J Sports Sci Routledge. 2018;36(22):2608-13.

27. Kim CH, Park JH, Kim H, Chung S, Park SH. Modeling the human body shape in Bioimpedance Vector Measurements. Conf Proc IEEE Eng Med Biol Soc. 2010;2010:3872-4. https://doi.org/10.1109/IEMBS.2010.5627664.

28. Galanti G, Stefani L, Scacciati I, Mascherini G, Buti G, Maffulli N. Eating and nutrition habits in young competitive athletes: a comparison between soccer players and cyclists. Transl Med @ UniSa. 2015;11(8):44-7.

29. Mala L, Maly T, Zahalka F, Bunc V, Kaplan A, Jebavy R, et al. Body composition of elite female players in five different sports games. J Hum Kinet. 2015:45(1):207-15.

30. Malý T, Malá L, Zahálka F, Baláš J, Čada M. Comparison of body composition between two elite Women's volleyball teams. Acta Univ Palacki Olomuc Gymn. 2011;41(1):15-22.
31. Levi Micheli M, Pagani L, Marella M, Gulisano M, Piccoli A, Angelini F, et al. Bioimpedance and impedance vector patterns as predictors of league level in male soccer players. Int J Sports Physiol Perform. 2014;9(3):532-9.

32. Hortobágyi T, Israel R, Houmard J, O'Brien K, Johns R, Wells J. Comparison of four methods to assess body composition in black and white athletes. Int J Sport Nutr. 1992;2:60-74.

33. Levi Micheli M, Gulisano M, Morucci G, Punzi T, Ruggiero M, Ceroti M, et al. Angiotensin-converting enzyme/vitamin d receptor gene polymorphisms and bioelectrical im-pedance analysis in predicting athletic performances of italian young soccer players. J ofStrength Cond Res. 2011;25:2084-91.

34. Ney JG, Koury JC, Azeredo VB, Casimiro-Lopes G, Trugo NMF, Torres AG. Associations of $n-6$ and n-3 polyunsaturated fatty acids and tocopherols with proxies of membrane stability and subcutaneous fat sites in male elite swimmers. Nutr Res Elsevier Inc. 2009;29(9):623-30.

35. Koury JC, de Oliveira-Junior AV, Portugal MRC, de JF DOK, Donangelo CM. Bioimpedance parameters in adolescent athletes in relation to bone maturity and biochemical zinc indices. J Trace Elem Med Biol. Elsevier. 2017:46:26-31.

36. Moreno M-V, Moreno G, Hubert F. Monitoring of bioimpedance data during exercise in cyclists. Orig Artic Proc 7th ISEA Conf 2008. 2008;

37. Irurtia A, Carrasco M, Rodriguez-Zamora L, Iglesias X, Brotons D, Rodriguez FA. Bioelectrical impedance vector migration induced by training in young competitive synchronised swimmers. XIlth International Symposium for Biomechanics and Medicine in Swimming. 2014. p. 426-431. https://doi.org/ 10.13140/2.1.2525.6962

38. Mascherini G, Cattozzo A, Petri C, Francini L, Galanti G. Application of Bioelectrical Vector Analysis in Professional Soccer Players - BIVA in Sport. In Proceedings of the 2nd International Congress on Sports Sciences Research and Technology Support (icSPORTS-2014), pages 84-88 ISBN: 978-989-758-057-4.

39. Mascherini G, Gatterer H, Lukaski H, Burtscher M, Galanti G. Changes in hydration, body-cell mass and endurance performance of professional soccer players through a competitive season. J Sports Med Phys Fitness. 2015;55:749-55.

40. Marra M, Da Prat B, Montagnese C, Sgroi M, Sicilia G, Caldara A, et al. Body composition changes in professional cyclists during the 2011 Giro d'Italia, a 3-week stage race. Nutr Ther Metab. 2014;32(1):31-4.

41. Marra M, Da Prat B, Montagnese C, Caldara A, Sammarco R, Pasanisi F, et al. Segmental bioimpedance analysis in professional cyclists during a three week stage race. Physiol Meas IOP Publishing. 2016;37(7):1035-40.

42. Pollastri L, Lanfranconi F, Tredici G, Burtscher M, Gatterer H. Body water status and short-term maximal power output during a multistage road bicycle race (Giro d'ttalia 2014). Int J Sports Med. 2015;37(04):329-33.

43. Mala L, Maly T, Zahalka F, Dragijsky M. Changes in body composition due to weight reduction by elite youth judo athletes in short period precompetition. Arch Budo Sci Martial Arts Extrem Sport. 2016;12:197-203.

44. Melchiorri G, Viero V, Sorge R, Triossi T, Campagna A, Volpe SL, et al. Body composition analysis to study long-term training effects in elite male water polo athletes. J Sports Med Phys Fitness. 2018;58(9):1269-1274. https://doi. org/10.23736/S0022-4707.17.07208-5.

45. Campa F, Matias CN, Marini E, Heymsfield SB, Toselli S, Silva AM. Identifying Athlete Body-Fluid Changes During a Competitive Season With Bioelectrical Impedance Vector Analysis. Int J Sports Physiol Perform. 2019;11:1-7. https:// doi.org/10.1123/ijspp.2019-0285.

46. Roberts J, Zinchenko A, Suckling C, Smith L, Johnstone J, Henselmans M. The short-term effect of high versus moderate protein intake on recovery after strength training in resistance-trained individuals. J Int Soc Sports Nutr. 2017;14(1):1-11.

47. Custodio Martins P, Seabra Moraes M, Santos Silva DA. Cell integrity indicators assessed by bioelectrical impedance: a systematic review of studies involving athletes. J Bodyw Mov Ther. 2019. https://doi.org/10.1016/j.jbmt.2019.05.017.

48. Schmidt SC, Bosy-westphal A, Niessner C, Woll A. Representative body composition percentiles from bioelectrical impedance analyses among children and adolescents: The MoMo study. Clin Nutr. 2018;(18)32559-7. https://doi.org/10.1016/j.clnu.2018.11.026.

49. Earthman CP. Body Composition Tools for Assessment of Adult Malnutrition at the Bedside: A Tutorial on Research Considerations and Clinical Applications Introduction to Lean Tissue Terminology. JPEN J Parenter Enteral Nutr. 2015;39(7):787-822. https://doi.org/10.1177/0148607115595227.

50. Wagner DR, Heyward VH. Review article measures of body composition in blacks and whites: a comparative. Am J Clin Nutr. 2000;71:1392-402.

\section{Publisher's Note}

Springer Nature remains neutral with regard to jurisdictional claims in published maps and institutional affiliations. 